\title{
Innovative Method for Coating of Natural Corrosion Inhibitor Based on Artemisia vulgaris
}

\author{
Daniel Alejandro Pineda Hernández ${ }^{1, *}$, Elisabeth Restrepo Parra ${ }^{1}$, Pedro José Arango Arango ${ }^{1}$, \\ Belarmino Segura Giraldo ${ }^{1}$ (D) and Carlos Daniel Acosta Medina ${ }^{2}$ \\ 1 Laboratorio de Física del Plasma, Unicversidad Nacional de Colombia sede Manizales, \\ Manizales-Caldas 170003, Colombia; erestrepopa@unal.edu.co (E.R.P.); pjarangoa@unal.edu.co (P.J.A.A.); \\ bsegurag@unal.edu.co (B.S.G.) \\ 2 Calculo Científico y Modelamiento Matemático, Universidad Nacional de Colombia sede Manizales, \\ Manizales-Caldas 170003, Colombia; cdacostam@unal.edu.co \\ * Correspondence: dapinedah@unal.edu.co; Tel.: +57-323-439-8093
}

Citation: Pineda Hernández, D.A.; Restrepo Parra, E.; Arango Arango, P.J.; Segura Giraldo, B.; Acosta

Medina, C.D. Innovative Method for Coating of Natural Corrosion Inhibitor Based on Artemisia vulgaris. Materials 2021, 14, 2234. https:// doi.org/10.3390/ma14092234

Received: 19 November 2020 Accepted: 24 December 2020 Published: 26 April 2021

Publisher's Note: MDPI stays neutral with regard to jurisdictional clai$\mathrm{ms}$ in published maps and institutional affiliations.

Copyright: (C) 2021 by the authors. Licensee MDPI, Basel, Switzerland. This article is an open access article distributed under the terms and conditions of the Creative Commons Attribution (CC BY) license (https:// creativecommons.org/licenses/by/ $4.0 /)$.

\begin{abstract}
In this work, the production of a novel methodology for the application of natural corrosion inhibitors on steel, using an autoclave is presented. Tests were carried out using Artemisia vulgaris. The inhibitor was produced with a simple soxhlet extraction process using $15 \mathrm{~g}$ of Artemisia vulgaris and $260 \mathrm{~mL}$ of Ether. Once the inhibitor was produced, the steel was immersed in it, to form a coating that protects the material against corrosion. Thermogravimetry analyzes (TGA) were performed on the inhibitor, to determine the degradation temperature; it was observed that, at $321{ }^{\circ} \mathrm{C}$, the loss of organic mass begins. After applying the inhibitor to the steel, the Fourier Transform Infrared Spectroscopy (FTIR) technique was used to determine the vibrational bands and the difference between the spectra for the steels before and after the coating was applied. For the evaluation of the method efficiency, Electrochemical Impedance Spectroscopy (EIS) and polarization resistance tests were performed, where Nyquist diagrams and Tafel curves were obtained, for steels with and without treatment. In this case, an increase of $93 \%$ in the corrosion resistance, and an $88 \%$ decrease in the corrosion rate were observed, proving that this methodology can be used to protect steel against corrosion and extend the steel's useful life.
\end{abstract}

Keywords: EIS; organic coating; tafel; mild steel; corrosion

\section{Introduction}

Each minute, 300 tons of steel are dissolved around the world due to corrosion, generating millions in losses for governments [1,2]. Due to this phenomenon, corrosion emerges as one of the biggest problems in the modern world, which makes it necessary to develop more efficient protection and prevention solutions against corrosion. To counter this problem, researchers have proposed solutions such as coatings [3], paints [4], thin films [5], corrosion inhibitors [6-8], among others; however, currently, one of the most important requirements for anti-corrosion solutions is that they should be as little polluting as possible.

In this field, corrosion inhibitors produced from natural sources are very promising.

Corrosion inhibitors are substances that, when added in small amounts to a corrosive medium, can decrease the rate of deterioration of the material through passivation [7]. There are several commercial corrosion inhibitors, which are widely used by the industry. These inhibitors are a useful tool in the battle against corrosion, as they reduce costs and improve the useful life of the material [8]. However, the composition of most of these corrosion inhibitors is unknown; besides, these corrosion inhibitors are toxic and environmentally harmful substances. In addition, they could be dangerous for the personnel who handle them. For this reason, in the last decade, governments have created regulations such as the Toxic Substances Control Act of the United States Environmental Protection Agency (EPA) and the European Union's Restriction of Hazardous Substances Directive [9]. 
These regulations demand that the products used in the industrial field must have the minimum possible toxicity. In order to search for options to comply with these laws, researchers worldwide are proposing the use of plant, fruit and/or flower extracts as corrosion inhibitors [10].

The study of corrosion inhibitors from natural sources has been advanced through systematic studies of plants and fruits on different types of metals, especially steel due to its wide range of applications. Thanks to these studies, a new horizon has been discovered, since these substances are very efficient under different corrosive conditions, with superior ecological properties since they are biodegradable. For instance, N. Soltani and collaborators [7] studied the inhibitory character of Salvia Officinalis in austenitic stainless steel 304; H. Herrera-Hernández et al. [8] investigated aloe vera gel on structural reinforcing steel, finding that this type of inhibitors are highly efficient for the protection of steels in different corrosive medium with protection efficiencies greater than $80 \%$ in comparison with steels without inhibitor addition, and many reports show that this type of inhibitor increases the useful life of materials by $80-90 \%$ [11-13].

Specifically referring to Artemisia vulgaris as a corrosion inhibitor, in 2012, Subhadra Garai and collaborators, from the National Metallurgy Laboratory of Jamshedpur, India, studied the inhibitory character of this plant. In this work, it was determined that the methanoic extract of Artemisia vulgaris shows efficiencies of $93 \%$ in $1 \mathrm{~mol} \mathrm{~L}^{-1} \mathrm{HCl}$ [6]. Artemisia vulgaris is a plant belonging to the Asteraceae family. Despite being considered undergrown, this family of plants has been studied extensively due to their antibacterial, antiseptic, and antioxidant properties. It grows in temperate climates and is native to Europe [14].

Generally, applying this type of corrosion inhibitors to the corrosive medium shows a considerable disadvantage at the application level against other types of solutions, such as paints or coatings. Unlike previous works related to corrosion inhibitors from natural sources, this work proposes an innovative, economical, and viable solution, which consists of the inhibitor adsorption by the metal using a hydrothermal process. The process generates optimal conditions for the creation of a natural extract layer that acts as a corrosion inhibitor. For an initial test, the work carried out by N. Soltani and collaborators was considered, since they used Artemisia vulgaris as a corrosion inhibitor for structural steel in a $1 \mathrm{~mol} \mathrm{~L}^{-1} \mathrm{HCl}$ solution, and based on this work, the autoclave method was applied.

\section{Materials and Methods}

\subsection{Extraction and Inhibitor Application}

Figure 1 shows a diagram of the methodology used to extract the corrosion inhibitor from Artemisia vulgaris, and its application to the steel samples employing the autoclave. To carry out the extraction, leaves were taken from the plant and a drying process was carried out in a Humboldt MFG oven. The samples were in a Model 40 Go lab oven at $60{ }^{\circ} \mathrm{C}$ for $24 \mathrm{~h}$, afterwards, they were macerated until a fine powder was produced [15]. A sample of $20 \mathrm{~g}$ of this powder was taken and using a Soxhlet, the extract was prepared in $260 \mathrm{~mL}$ of ether for $4 \mathrm{~h}$. Afterward, the ether solution was distilled to concentrate the extract until $20 \mathrm{~mL}$ of solution was acquired [16]. After that, a thermogravimetric analysis of the extract was carried out, to determine the degradation temperature. The structural steel samples to be coated must be partially polished and cleaned with acetone to remove any dirt from the surface.

For optimal working conditions, a systematic study was conducted varying the temperature from $60^{\circ} \mathrm{C}$ to $200{ }^{\circ} \mathrm{C}$ with a step of $20^{\circ} \mathrm{C}$ in the hydrothermal process. It was observed that at low temperatures, the coating was not formed and at high temperatures the extract was calcined. The temperature at which the coating showed better characteristics was $120^{\circ} \mathrm{C}$; then, this temperature was selected for developing the process of coating the steel.

After the extract was obtained and the steel samples were thoroughly cleaned, they were put into the autoclave, and it was hermetically sealed and heated. This heating was carried 
out with a filling factor of $30 \%$. In this filling factor, $20 \%$ of the volume corresponded to the extract and approximately $10 \%$ to the metal immersed in it. The heating was carried out for $40 \mathrm{~min}$. At the end of this time, the sample was extracted, dried under normal environmental conditions, and the tests were subsequently carried out. To develop this experiment, a stainless-steel autoclave with a total volume of $100 \mathrm{~mL}$ was used; inside the autoclave, there is a Teflon container to prevent the reaction of external compounds during the creation of the coating. Figure 1 shows a diagram that describes the experimental process to make the coatings.

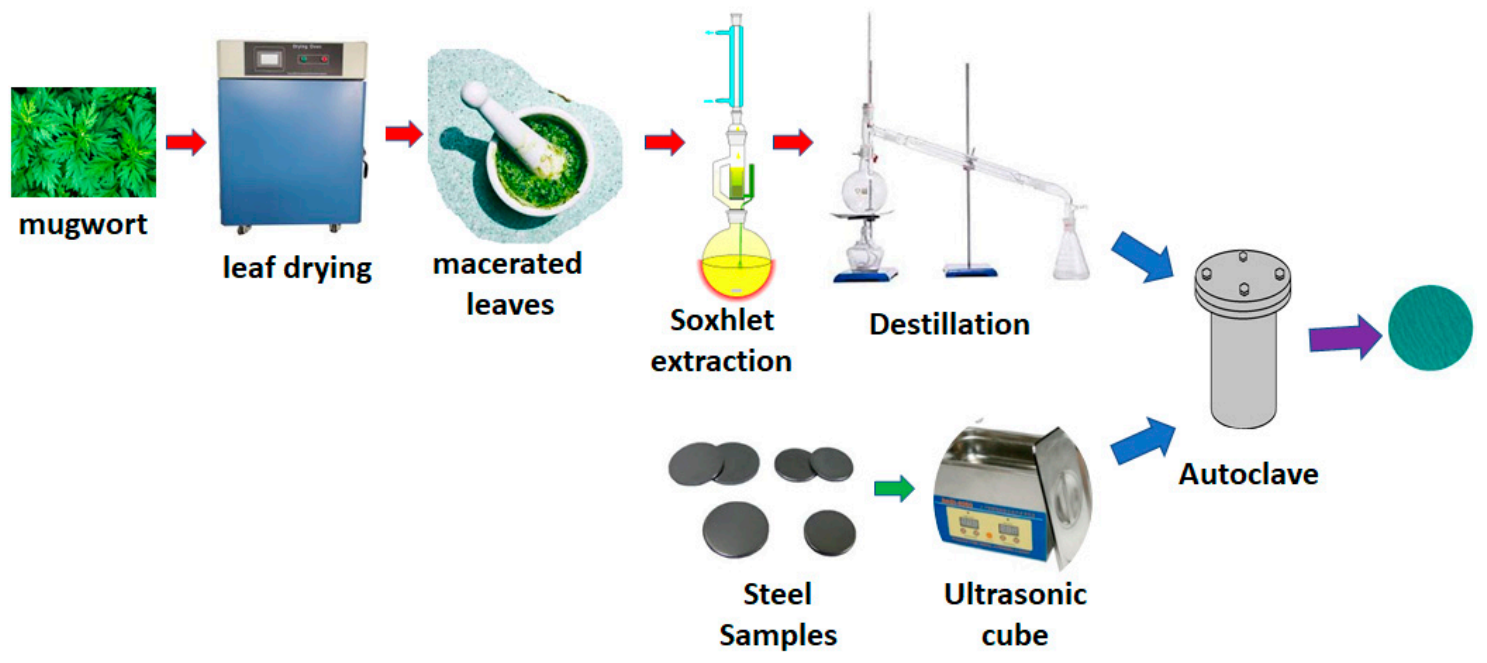

Figure 1. Experimental setup.

\subsection{Materials Characterization}

Fourier transform infrared spectroscopy (FTIR) was used to determine the functional groups in the Artemisia vulgaris extract and the coatings on the structural steel. For this analysis, a BRUKER alpha platinum equipment with an ATR platinum Diamond 1 accessory was used. The characterization was carried out with a resolution of $4 \mathrm{~cm}^{-1}, 32$ steps and a measurement range from 400 to $4000 \mathrm{~cm}^{-1}$; at the same time, a thermogravimetric analysis using a TGA Q500 V6.7 Build 203 was performed to determine the degradation temperature of the extract. A heating rate of $293.15 \mathrm{Kmin}^{-1}$ was applied until reaching $800{ }^{\circ} \mathrm{C}$. A nitrogen atmosphere was used with a flow of $60 \mathrm{~mL} \mathrm{~min}^{-1}$. To evaluate the efficiency of the coating, electrochemical impedance, and polarization resistance spectroscopy was performed to determine corrosion resistance and corrosion rate using a Gamry 1000E potentiostat/galvanostat. EIS tests were performed in a range of $10^{6}$ to $10^{-3} \mathrm{~Hz}$ employing $0.1 \mathrm{~mol} \mathrm{~L}^{-1} \mathrm{HCl}$ as a corrosive medium, while TAFEL tests were performed according to ASTM G59 recommendations [17].

\section{Results}

\subsection{Compositional Characterization}

\subsubsection{Fourier Transform Infrared}

Figure 2 shows the spectrum for the concentrated extract. A large number of $\mathrm{CO}$, $\mathrm{CH}$ and $\mathrm{CC}$ bonds, characteristic of organic substances, was observed. The results are listed in Table $1[18,19]$. 


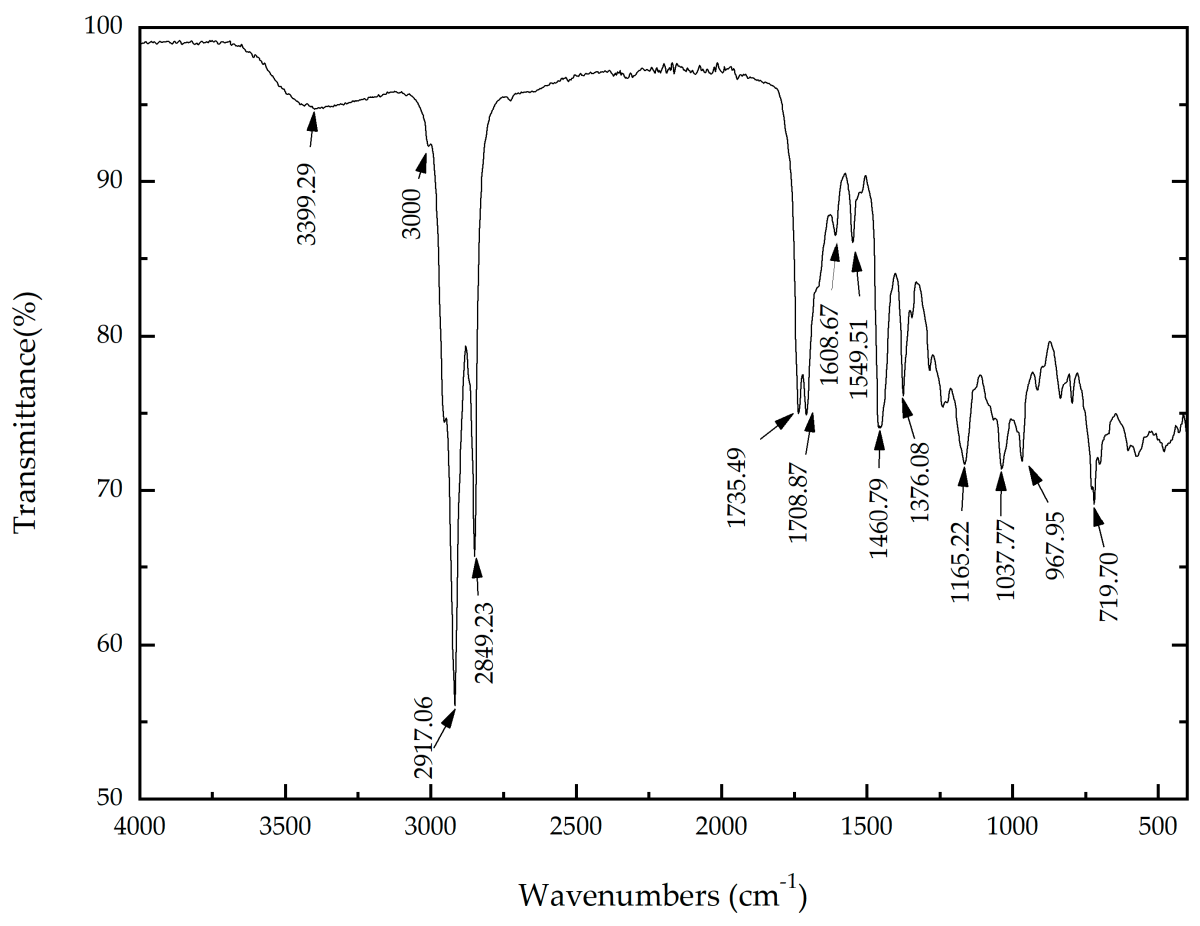

Figure 2. FTIR transmittance spectrum for Artemisia vulgaris extract.

Table 1. FTIR spectrum identification for Artemisia vulgaris extract.

\begin{tabular}{|c|c|c|}
\hline Wavenumber $\left(\mathrm{cm}^{-1}\right)$ & Compound & Notes \\
\hline 3399.29 & $\mathrm{OH}$ & Associated with a polymeric primary alcohol (carrier substance) \\
\hline 3000 & \multirow{5}{*}{$-\mathrm{CH}_{2-}^{-}$} & Vs \\
\hline 2917.06 & & Vas \\
\hline 2849.23 & & Vs \\
\hline 1460.79 & & Scissor \\
\hline 719.70 & & Rocking \\
\hline 1376.08 & $\mathrm{O}-\mathrm{CO}-\mathrm{CH}_{3}$ & \\
\hline 1549.51 & & \multirow{2}{*}{ Confirmed presence of aromatic rings with benzene nucleus. } \\
\hline 1608.67 & & \\
\hline 1165.22 & & \multirow{3}{*}{ They give information about the branches that the ring presents. } \\
\hline 1037.77 & & \\
\hline 967.94 & & \\
\hline 1735.49 & & Esters \\
\hline 1708.87 & & Carboxylic acids \\
\hline
\end{tabular}

Figure 3 shows the comparison between the spectra for the coating, and the extract. It is possible to identify the functional groups in each of the cases. The conservation of most of the compounds in the steel coated according to the extract can be observed. This is because the steel adsorbed several substances from the extract. In both cases, some bands correspond to hydroxy-phenolic groups $\left(3336.4 \mathrm{~cm}^{-1}\right)$, aromatic groups $\left(1653.94 \mathrm{~cm}^{-1}\right)$, groups that, according to the literature, are the ones that improve corrosion inhibition $[6,20-22]$. On the 
other hand, changes in the intensities of some peaks of the extract were observed once applied to the steel. This effect is because the steel adsorption of species is not total and therefore, the concentration of each substance is lower. The preservation of the compounds that inhibit corrosion on the surface of the steel coating is because a thermogravimetric analysis was previously carried out to find the temperature at which the extract begins to degrade. Once the degradation temperature was known, the coating process was carried out at a temperature lower than the one found in the thermogravimetric analysis.
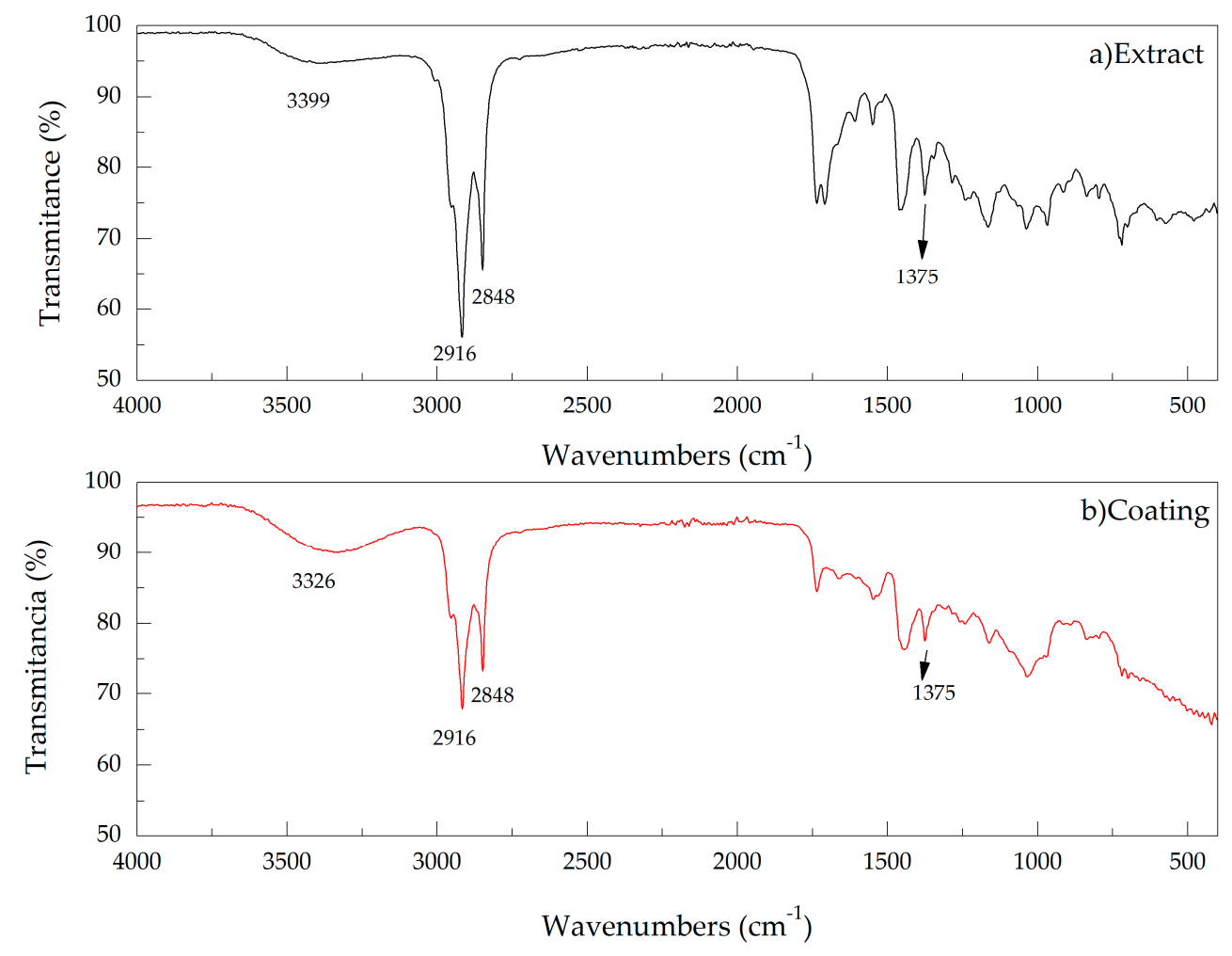

Figure 3. FTIR transmittance spectrum for (a) Artemisia vulgaris extract (b) coating of Artemisia vulgaris.

\subsubsection{Thermogravimetric Analysis}

In Figure 4, the thermal decomposition curve obtained by the thermogravimetric analysis of the Artemisia vulgaris extract is presented. The decomposition of the extract as a function of temperature can be observed, showing critical points of mass loss. It can be deduced that the first significant loss of mass, corresponding to $20.25 \mathrm{wt} \%$ of the total, begins at $52.2{ }^{\circ} \mathrm{C}$ with the surface water and ends between $100-105^{\circ} \mathrm{C}$ with bound water [23]. Subsequently, at higher temperatures, between $125-350{ }^{\circ} \mathrm{C}, 29.22 \%$ of the mass is lost, corresponding to the $\mathrm{C}=\mathrm{O}$ bonds and the decomposition of the $\mathrm{OH}$ groups $[11,18]$.

Table 2 shows in detail the loss of mass with the increase of temperature, however, since in this investigation it is required for the extract to remain as intact as possible, the working temperature must be lower than the first critical point of mass loss, that is, less than $325^{\circ} \mathrm{C}$. For this reason, it was decided to coat the steel with the extract inside the autoclave, at a temperature of $120^{\circ} \mathrm{C}$, at which the compound has not been degraded. 


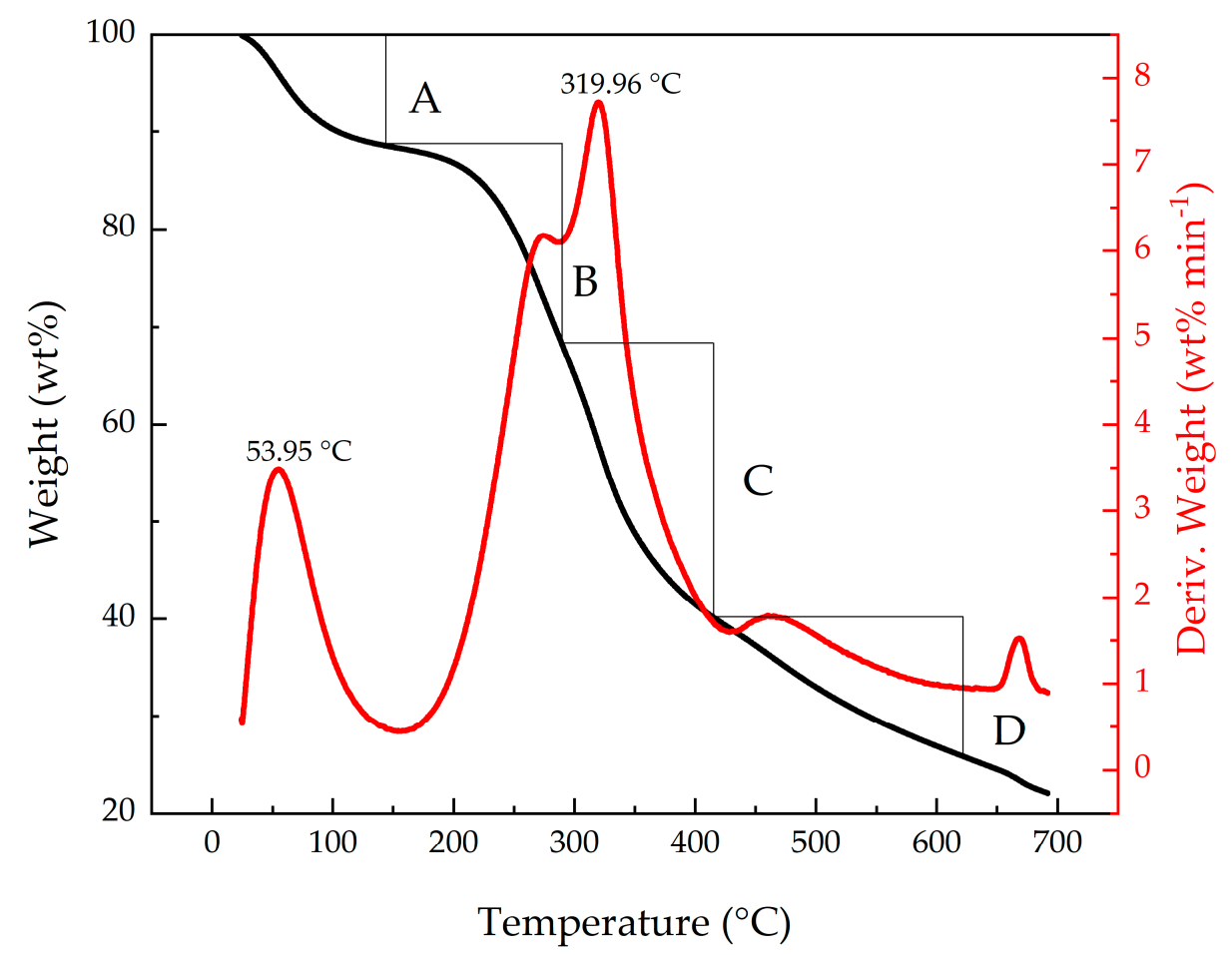

Figure 4. Thermal Decomposition Curve of the corrosion inhibitor produced from the Artemisia vulgaris.

Table 2. Mass loss percentage.

\begin{tabular}{ccc}
\hline & \% Weight & Temperature $\left({ }^{\circ} \mathbf{C}\right)$ \\
\hline A & 11.38 & 52.24 \\
B & 20.25 & 288.28 \\
C & 29.22 & 321.64 \\
D & 13.07 & 618.45 \\
\hline
\end{tabular}

\subsection{Electrochemical Measurements}

Figure 5 shows the Nyquist diagram from the electrochemical impedance spectroscopy technique. The black and red curves correspond to uncoated and coated steel samples, respectively. From this figure, it is observed that the coated steel exhibits a much greater radius of curvature than the uncoated steel, which indicates a noticeable increase in the corrosion resistance. The efficiency of the coating was calculated using Equation (1), where $\%$ ef is the coating efficiency, SS and SR the corrosion resistance of the steel and the coated steel, respectively, [24-27], finding an increase of $92.91 \%$ in the corrosion resistance, as shown in Table 3.

$$
\% \text { ef }=\frac{S S-S R}{S R} * 100 \%
$$

The behavior of treated and untreated steel can be modeled from electronic components to understand better the electrical behavior of the corrosion process. The equivalent circuits for untreated and treated steel, respectively, are shown in Figure 6a,b.

Figure 6 shows the different components that model the electrochemical behavior of the structural steel surface with and without treatment. $R_{u}$ is related to the resistance of the aqueous solution. $Y_{0}$ is a constant phase element associated with the electronic double layer capacitance, created on the interface surface of the working and solution electrode; however, since it is not an ideal capacitance due to roughness and possible pores on the surface of the steel, with an ideality factor $\alpha$, the gerischer element $G$, that is found only in the equivalent circuit of the treated steel, is an indication of the porosity of the organic coating with a porosity factor $\mathrm{K}$, the gerischer element is necessary to explain the reaction 
of the organic coating, because the reactions between the two surfaces, the surface of the steel and the organic coating, cannot be distinguished from each other [28]. Finally, $R_{p}$ is the polarization resistance or corrosion resistance of the material $[27,29,30]$. This variable is the one of interest for the study. Tables 3 and 4 show the values of these elements.

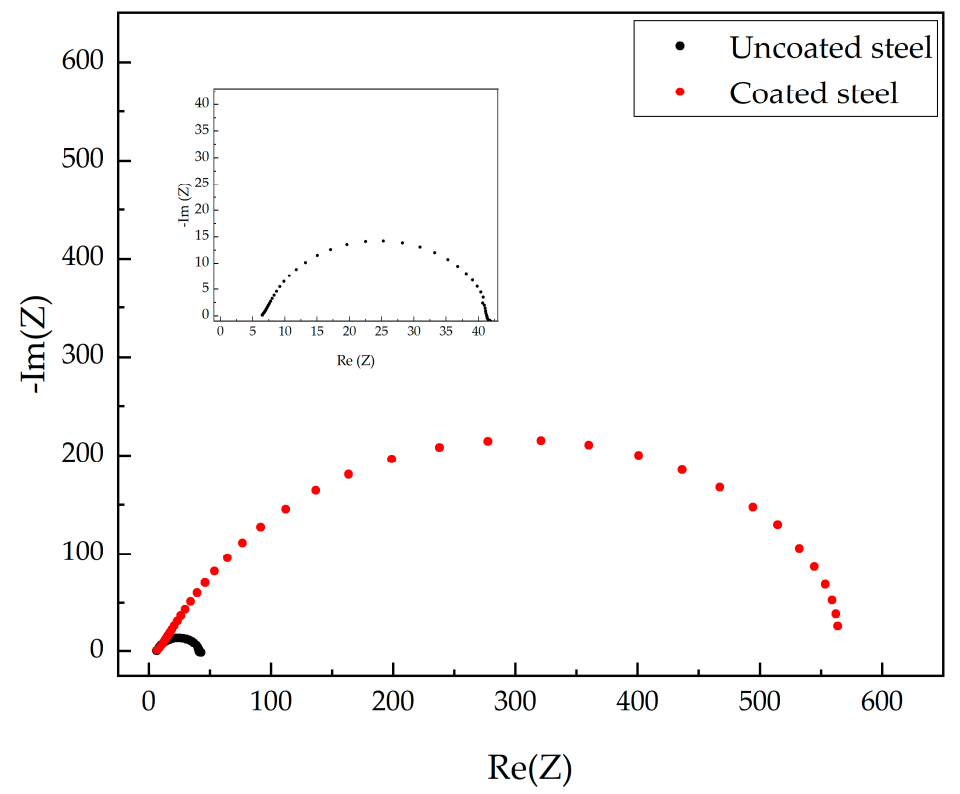

Figure 5. Nyquist plot of mild steel in $0.1 \mathrm{~mol} \mathrm{~L}^{-1} \mathrm{HCl}$ with and without the coating of Artemisia vulgaris extract.

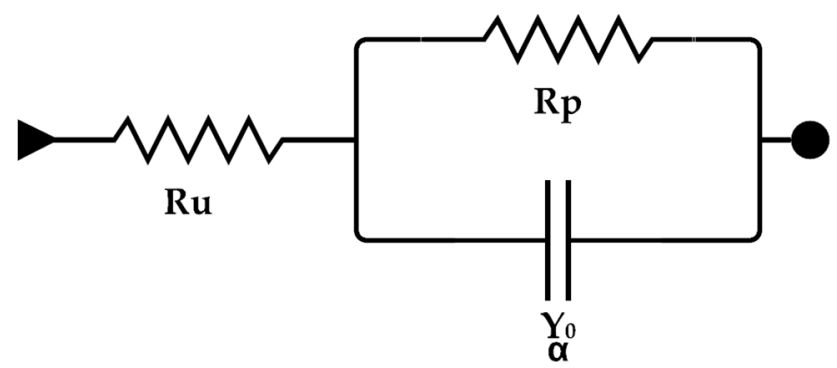

(a)

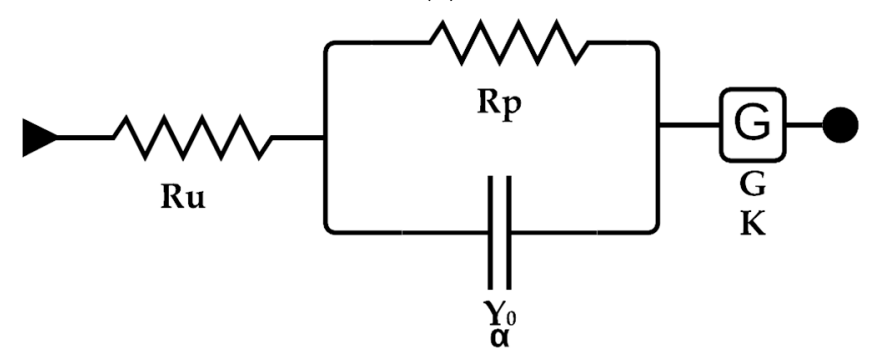

(b)

Figure 6. Equivalent circuits for (a) uncoated steel (b) coated steel.

By using the potentiodynamic curves, different data can be obtained regarding the phenomena occurring in the corrosion and inhibition processes once the extract is applied to the Steel. In addition to obtaining information on the adsorption of the inhibitor employing an autoclave. Figure 7 shows the Tafel polarization curves corresponding to uncoated and coated steel samples. This figure shows an inhibitory behavior of an anodic nature since it moves towards the anodic part of the curve. This anodic inhibition behavior is 
related to the formation of films on the steel surface due to external printed currents [31,32]. Furthermore, it is observed that the corrosion rate is reduced by $32.6 \%$, with respect to the corrosion rate of the untreated steel. This decrease is because the inhibitor generates an oxidoreduction reaction process, delaying the release of ions from the Steel, which is proof of the efficiency of the coating. Table 5 show the corrosion resistances (Rcorr) and corrosion rate of uncoated and coated steel with the efficiency shown for each parameter.

Table 3. Value of equivalent circuit components for uncoated steel.

\begin{tabular}{cccc}
\hline Element & Value & \pm Error & Units \\
\hline $\mathbf{R}_{\mathbf{u}}$ & 6.607 & $40.05 \times 10^{-5}$ & $\Omega$ \\
$\mathbf{Y}_{\mathbf{0}}$ & $454.4 \times 10^{-6}$ & $19.95 \times 10^{-6}$ & $\mathrm{~S} \times \mathrm{s}^{\alpha}$ \\
$\alpha$ & $841.6 \times 10^{-3}$ & $7.136 \times 10^{-3}$ & - \\
$\mathbf{R}_{\mathbf{p}}$ & 35.53 & $289.7 \times 10^{-3}$ & $\Omega$ \\
\hline
\end{tabular}

Table 4. Value of equivalent circuit components for coated steel.

\begin{tabular}{cccc}
\hline Element & Value & \pm Error & Units \\
\hline $\mathbf{R}_{\mathbf{u}}$ & 6.101 & $97.19 \times 10^{-3}$ & $\Omega$ \\
$\mathbf{Y}_{\mathbf{0}}$ & $59.29 \times 10^{-6}$ & $5.415 \times 10^{-6}$ & $\mathrm{~S} \times \mathrm{s}^{\alpha}$ \\
$\boldsymbol{\alpha}$ & $890 \times 10^{-3}$ & $12.38 \times 10^{-3}$ & - \\
$\mathbf{G}$ & $1232 \times 10^{-3}$ & $55.50 \times 10^{-6}$ & $\mathrm{~S} \times \mathrm{s}^{\left(\frac{1}{2}\right)}$ \\
$\mathbf{K}$ & 181.5 & 77.64 & $\mathrm{~s}^{-1}$ \\
$\mathbf{R}_{\mathbf{p}}$ & 501.2 & 13.24 & $\Omega$ \\
\hline
\end{tabular}

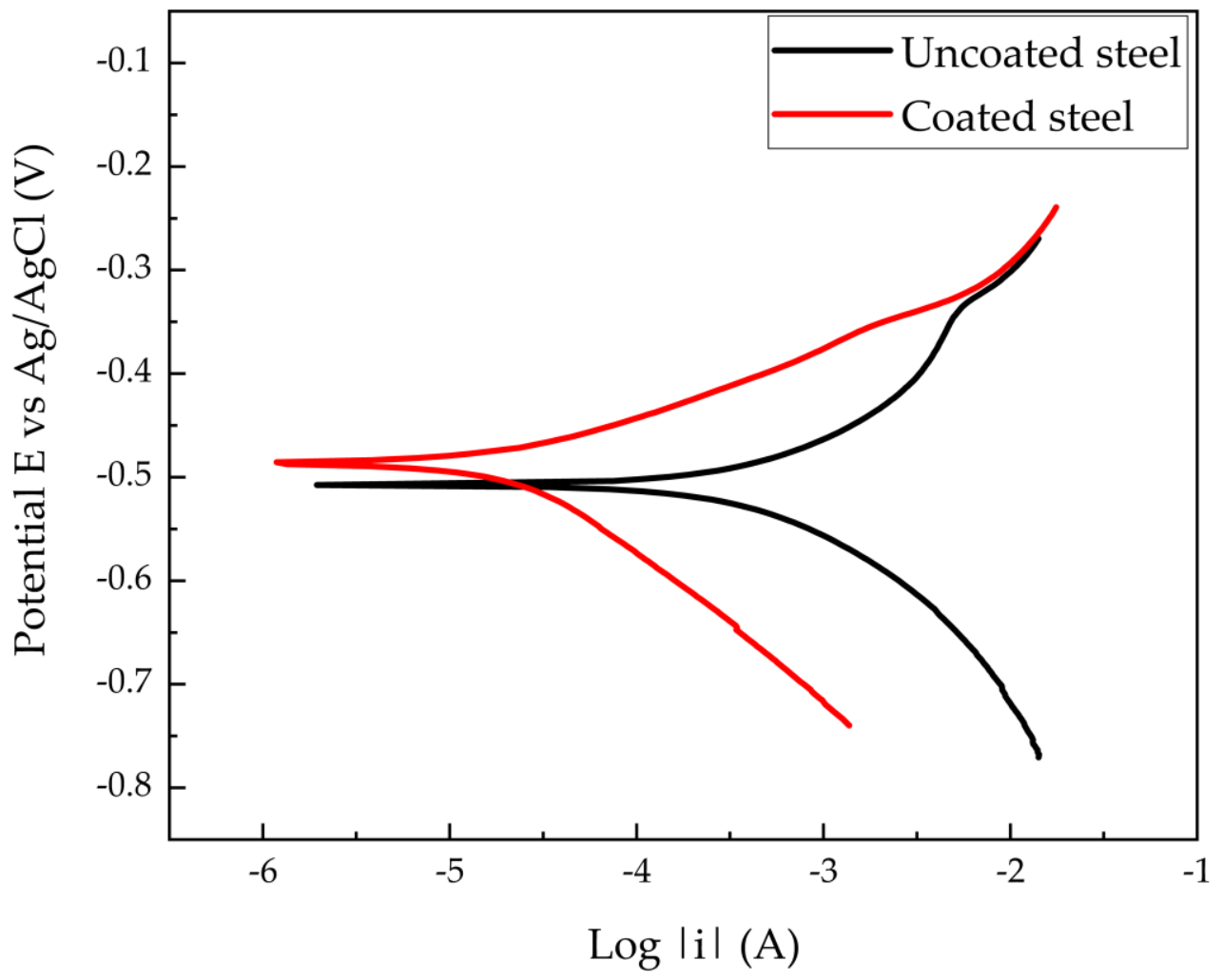

Figure 7. Potentiodynamic curves of mild steel in $0.1 \mathrm{~mol} \mathrm{~L}^{-1} \mathrm{HCl}$ with and without coating of Artemisia vulgaris extract. 
Table 5. Results from the electrochemical tests.

\begin{tabular}{cccc}
\hline Sample $\backslash$ Charact. & Uncoated Steel & Coated Steel & \%Efficiency \\
\hline Rcorr $(\boldsymbol{\Omega})$ & $35.53 \pm 289.7 \times 10^{-3}$ & $501.2 \pm 13.24$ & $92.91 \%$ \\
Corrosion Rate (mpy) & 52.3 & 6.34 & $88.31 \%$ \\
\hline
\end{tabular}

\subsection{Visual Inspection}

Figure 8 shows the micrographs of the structural steel samples with and without coating before the corrosion measurements. Figure $8 \mathrm{a}, \mathrm{b}$ show the polished structural steel with the characteristic shine of the steel. In Figure $8 \mathrm{c}, \mathrm{d}$, the steel coated with Artemisia vulgaris is presented. When these two samples are compared, a difference in their brightness is observed, the sample in Figure 8c,d shows an opacity in addition to a jade green pigmentation developed due to the coating.

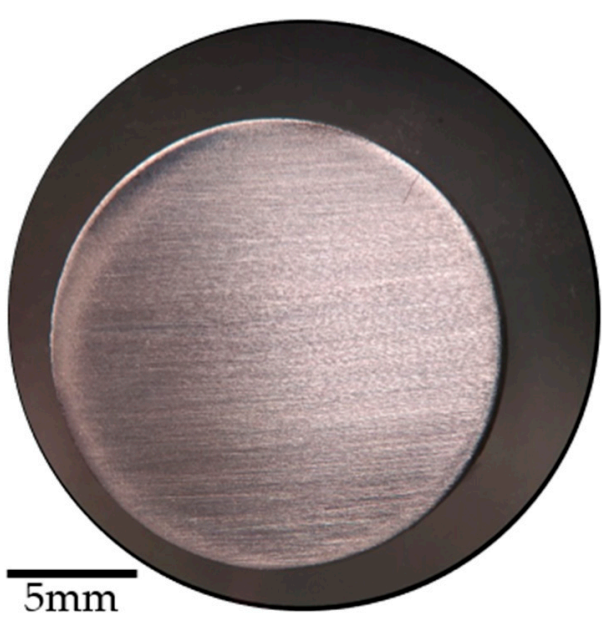

(a)

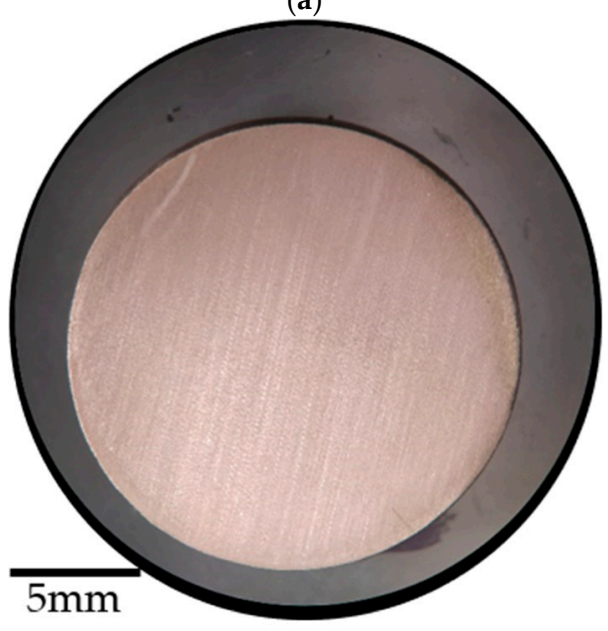

(c)

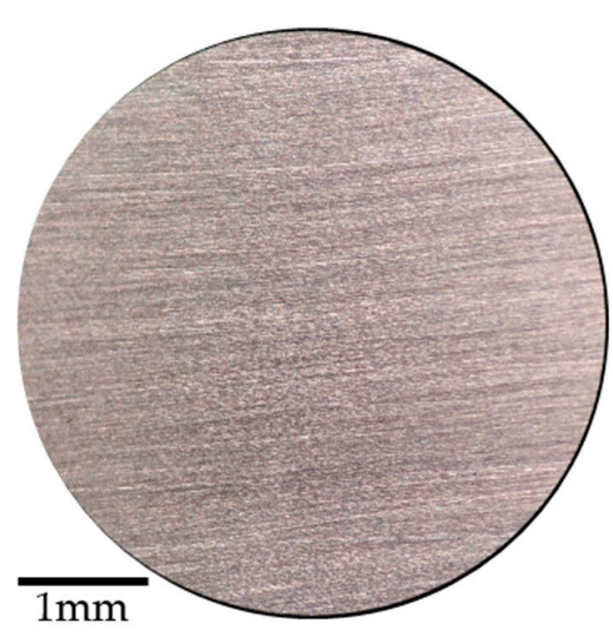

(b)

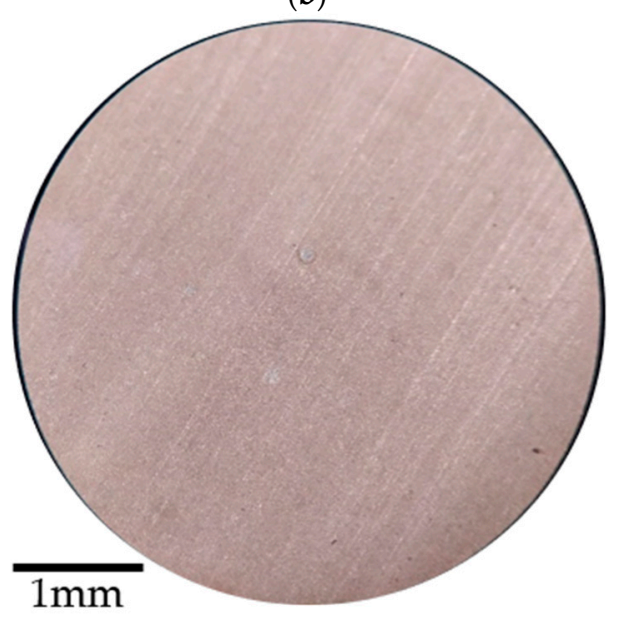

(d)

Figure 8. Micrographs before corrosion of structural steel (a) polished with magnification $1 \times$, (b) polished with magnification $5 \times,($ c) coated with magnification $1 \times$, and $(\mathbf{d})$ coated with magnification $5 \times$.

Figure 9 shows the micrographs corresponding to the samples after the corrosion measurements. Figure 9a shows the corrosion of the mild steel sample, where localized sources of corrosion are present. When these corrosion points are seen more closely in Figure $9 b$, characteristic pitting corrosion is evident in this type of steel. On the other hand, in Figure $9 \mathrm{c}, \mathrm{d}$ it is observed that the sample coated with Artemisia vulgaris changed its color 
from jade green to an opaque brown, as a consequence of the reaction between the phenols and flavonoids of the coating with the medium corrosive [33].

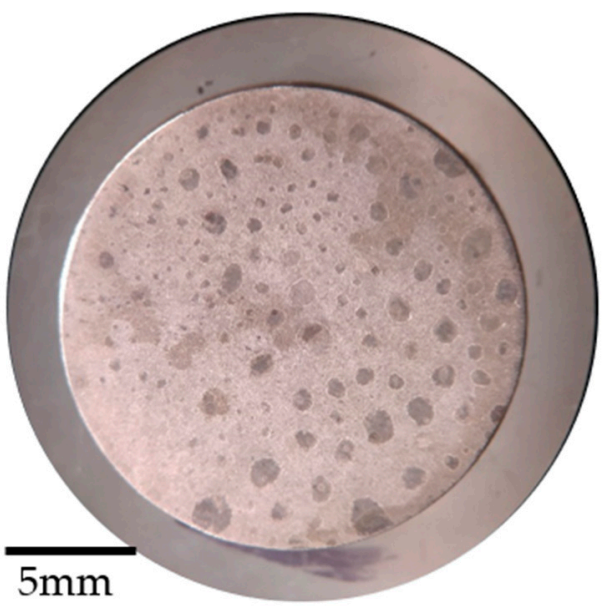

(a)

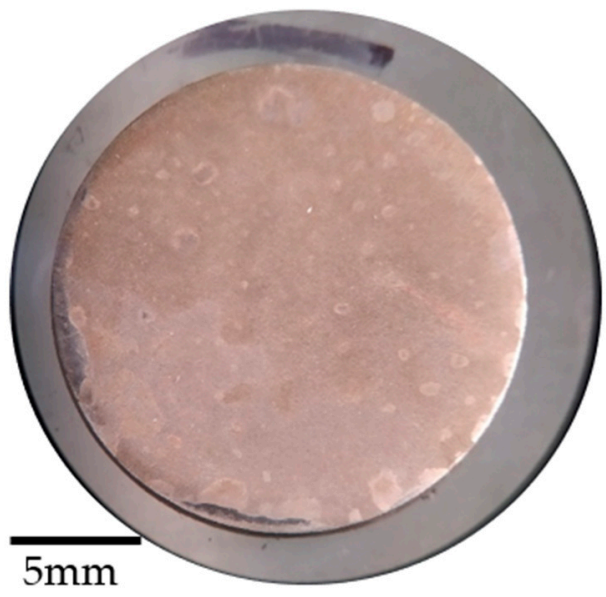

(c)

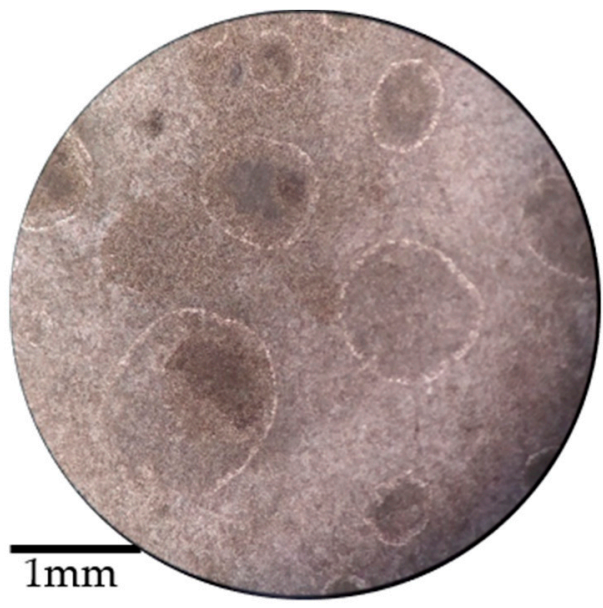

(b)

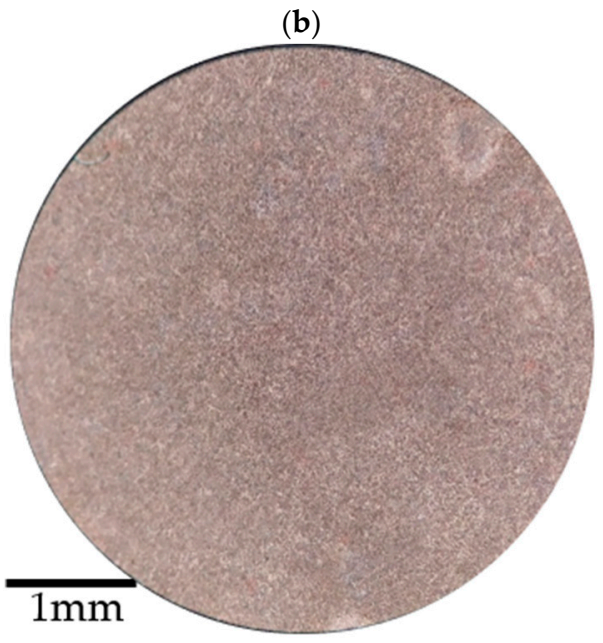

(d)

Figure 9. Micrographs after corrosion measurements of structural steel (a) polished with magnification $1 \times,(\mathbf{b})$ polished with magnification $5 \times,(\mathbf{c})$ coated with magnification $1 \times$, and $(\mathbf{d})$ coated with magnification $5 \times$.

Figure 10 shows the coating inhibition method. The protection provided by Artemisia vulgaris coating is possible thanks to the ability of phenols to trap oxygen and hydrogen in their free radicals [33,34], phenols being part of the oxidation process while the steel is protected. 


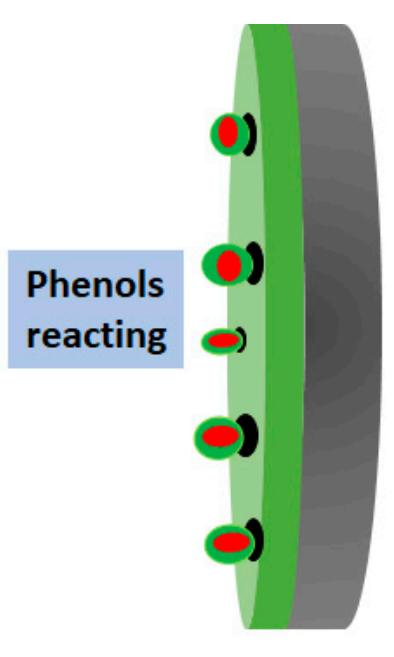

(a)

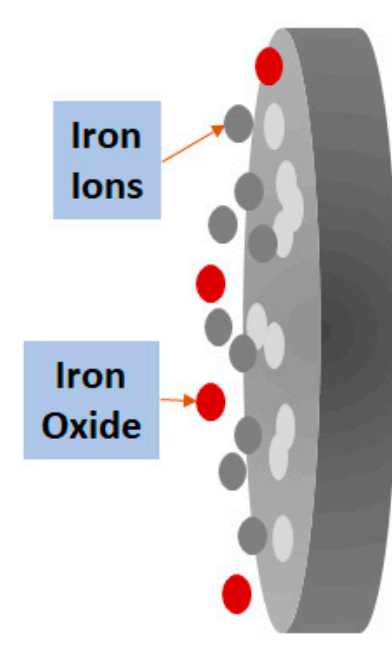

(b)

Figure 10. Schematic description of the phenomenology occurring for the prevention of deterioration by coating with natural corrosion inhibitors; (a) corrosion phenomenology with coating; (b) corrosion phenomenology without coating.

\section{Conclusions}

A natural corrosion inhibitor coating was obtained from the Artemisia vulgaris plant using the autoclave method. TGA analyses showed that the material begins its degradation at $325{ }^{\circ} \mathrm{C}$. Then, lower temperatures must be used. Using FTIR, the vibrational bands in the coating and the Artemisia vulgaris extract were determined, observing hydroxyphenolic $\left(3336.4 \mathrm{~cm}^{-1}\right)$ and aromatic $\left(1653.94 \mathrm{~cm}^{-1}\right)$ groups that, according to the literature, help the inhibitory character of these substances. Corrosion resistance was determined using Nyquist diagrams, where a 59.95\% of increase in corrosion resistance was obtained. It is important to highlight that there is good adsorption of the inhibitor by the steel; this can be evidenced in the FTIR analyzes and in the corrosion tests, specifically in EIS, where the reaction of the coating and the substrate with the medium cannot be differentiated. In addition, it was determined that the corrosion current decreased and the voltage increased, which is an indication of an increase in the useful life of the steel, showing an improvement in the corrosion rate of $88.31 \%$.

This method was innovative and effective in protecting structural steels since it provides a homogeneous coating of the surface exposed to the treatment and should be studied to obtain a better understanding of the adsorption mechanisms.

Author Contributions: Conceptualization, D.A.P.H. and P.J.A.A., methodology, D.A.P.H.; validation, D.A.P.H.; formal analysis, D.A.P.H. and E.R.P.; investigation, D.A.P.H. and E.R.P.; resources, B.S.G. and C.D.A.M.; data curation, D.A.P.H.; writing-original draft preparation, D.A.P.H. and E.R.P.; visualization, D.A.P.H. and E.R.P.; supervision, E.R.P. All authors have read and agreed to the published version of the manuscript.

Funding: This research received no external funding.

Institutional Review Board Statement: Not applicable.

Informed Consent Statement: Not applicable.

Data Availability Statement: Data available on request due to restrictions eg privacy or ethical The data presented in this study are available on request from the corresponding author. The data are not publicly available due to these results are associated with an active project at the National University of Colombia.

Acknowledgments: The authors gratefully acknowledge financial support from the Universidad Nacional de Colombia. The authors express their gratitude to the research program entitled "Re- 
construcción del tejido social en zonas posconflicto en Colombia" SIGP code: 57579 with the project entitled "Competencias empresariales y de innovación para el desarrollo económico y la inclusión productiva de las regiones afectadas por el conflicto colombiano" SIGP code 58907. Contract number: FP44842-213-2018.

Conflicts of Interest: The authors declare no conflict of interest.

\section{References}

1. Reiche, H.A.T.; Derry, T.K.; Williams, T.I. A Short History of Technology from the Earliest Times to A.D. 1900. Class World 2010, 54, 296. [CrossRef]

2. Koch, G.; Varney, J.; Thompson, N.; Moghissi, O.; Gould, M.; Payer, J. NACE 2016 Impact Study; NACE International: Huston, TX, USA, 2016.

3. Jiang, L.; Syed, J.A.; Gao, Y.; Lu, H.; Meng, X. Electrodeposition of $\mathrm{Ni}(\mathrm{OH})_{2}$ reinforced polyaniline coating for corrosion protection of 304 stainless steel. Appl. Surf. Sci. 2018, 440, 1011-1021. [CrossRef]

4. Singh, A.K.; Alam, S.; Rani, N. Preparation and characterisation of acrylic-polyurethane-based waterborne anticorrosion coating on galvanised steel. Trans. IMF 2017, 95, 165-172. [CrossRef]

5. Zhou, F.; Ma, Q.; Wang, Q.; Zhou, Z.; Li, L.K.Y. Electrochemical and tribological properties of CrBCN coatings with various B concentrations in artificial seawater. Tribol. Int. 2017, 116, 19-25. [CrossRef]

6. Garai, S.; Garai, S.; Jaisankar, P.; Singh, J.K.; Elango, A. A comprehensive study on crude methanolic extract of Artemisia pallens (Asteraceae) and its active component as effective corrosion inhibitors of mild steel in acid solution. Corros. Sci. 2012, 60, 193-204. [CrossRef]

7. Soltani, N.; Tavakkoli, N.; Kashani, M.K.; Mosavizadeh, A.; Oguzie, E.E.; Jalali, M.R. Silybum marianum extract as a natural source inhibitor for 304 stainless steel corrosion in 1.0M HCl. J. Ind. Eng. Chem. 2014, 20, 3217-3227. [CrossRef]

8. Herrera-Hernández, H.; Franco-Tronco, M.I.; Miranda-Hernández, G.J.; Hernández-Sánchez, E.; Espinoza-Vázquez, A.; Fajardo, G. Gel de aloe-vera como potencial inhibidor de la corrosión del acero de refuerzo estructural. Av. Cienc. Ing. 2015, 6, 9-23.

9. EPA. The Environmental Protection (Controls on Dangerous Substances) Regulations 2003; Legislation: London, UK, 2003 ; Volume 57.

10. Patricia, L.; Benítez, T.; Javier, P.; Castellar, M.; David, E.; Percy, A. Uso de extractos de plantas como inhibidores de corrosión. Rev. Inf. Tec. 2014, 78, 155-165.

11. Nikpour, S.; Naderi, R.; Mahdavian, M. Fabrication of silane coating with improved protection performance using Mentha longifolia extract. J. Taiwan Inst. Chem. Eng. 2018, 88, 261-276. [CrossRef]

12. Umoren, S.A.; Eduok, U.M.; Solomon, M.M.; Udoh, A.P. Corrosion inhibition by leaves and stem extracts of Sida acuta for mild steel in $1 \mathrm{M} \mathrm{H}_{2} \mathrm{SO}_{4}$ solutions investigated by chemical and spectroscopic techniques. Arab. J. Chem. 2016, 9, S209-S224. [CrossRef]

13. Umoren, S.A.; Obot, I.B.; Israel, A.U.; Asuquo, P.O.; Solomon, M.M.; Eduok, U.M.; Udoh, A.P. Inhibition of mild steel corrosion in acidic medium using coconut coir dust extracted from water and methanol as solvents. J. Ind. Eng. Chem. 2014, 20, 3612-3622. [CrossRef]

14. Jakovljević, M.R.; Grujičić, D.; Vukajlović, J.T.; Marković, A.; Milutinović, M.; Stanković, M.; Vuković, N.; Vukić, M.; MiloševićDjordjević, O. In vitro study of genotoxic and cytotoxic activities of methanol extracts of Artemisia vulgaris L. and Artemisia alba Turra. S. Afr. J. Bot. 2020, 132, 117-126. [CrossRef]

15. Azwanida, N.N. A Review on the Extraction Methods Use in Medicinal Plants, Principle, Strength and Limitation. Med. Aromat. Plants 2015, 4, 3-8. [CrossRef]

16. Addo-Mensa, A.; Garcia, G.; Maldonado, I.A.; Anaya, E.; Cadena, G.; Lee, L.G. Evaluation of Antibacterial Activity of Artemisia vulgaris Extracts. Res. J. Med. Plant 2015, 9, 234-240. [CrossRef]

17. ASTM International. ASTM G59-Standard test method for conducting potentiodynamic polarization resistance measurements. ASTM Stand. 2014, 97, 1-4. [CrossRef]

18. Liang, T.; Wang, L. Preparation and characterization of a novel edible film based on Artemisia sphaerocephala Krasch. gum: Effects of type and concentration of plasticizers. Food Hydrocoll. 2018, 77, 502-508. [CrossRef]

19. Kouhbanani, M.A.J.; Beheshtkhoo, N.; Amani, A.M.; Taghizadeh, S.; Beigi, V.; Bazmandeh, A.Z.; Khalaf, N. Green synthesis of iron oxide nanoparticles using Artemisia vulgaris leaf extract and their application as a heterogeneous Fenton-like catalyst for the degradation of methyl orange. Mater. Res. Express 2018, 5, 115013. [CrossRef]

20. Oliveira, R.N.; Mancini, M.C.; de Oliveira, F.C.S.; Passos, T.M.; Quilty, B.; Da Silva Moreira Thiré, R.M.; McGuinness, G.B. FTIR analysis and quantification of phenols and flavonoids of five commercially available plants extracts used in wound healing. Matéria (Rio Janeiro) 2016, 21, 767-779. [CrossRef]

21. Jarial, R.; Shard, A.; Thakur, S.; Sakinah, M.; Zularisam, A.W.; Rezania, S.; Kanwar, S.S.; Singh, L. Characterization of flavonoids from fern Cheilanthes tenuifolia and evaluation of antioxidant, antimicrobial and anticancer activities. J. King Saud Univ. Sci. 2018, 30, 425-432. [CrossRef]

22. Cobaleda-Velasco, M.; Almaraz-Abarca, N.; Alanis-Bañuelos, R.E.; Uribe-Soto, J.N.; González-Valdez, L.S.; Muñoz-Hernández, G.; Zaca-Morán, O.; Rojas-López, M. Rapid Determination of Phenolics, Flavonoids, and Antioxidant Properties of Physalis ixocarpa Brot. ex Hornem. and Physalis angulata L. by Infrared Spectroscopy and Partial Least Squares. Anal. Lett. 2018, 51, 523-536. [CrossRef] 
23. Alshamsi, H.A.; Ali, S.K.; Altaa, S.H.A. Green Synthesis and Characterization of Reduced Graphene Oxide (RGO) Using Sabdarriffa L Extract and Its Solubility Property. J. Phys. Conf. Ser. 2020, 1664, 012058. [CrossRef]

24. Afia, L.; Hamed, O.; Larouj, M.; Lgaz, H.; Jodeh, S.; Salghi, R. Novel Natural Based Diazepines as Effective Corrosion Inhibitors for Carbon Steel in HCl Solution: Experimental, Theoretical and Monte Carlo Simulations. Trans. Indian Inst. Met. 2017, 70, $2319-2333$. [CrossRef]

25. Verma, D.; Khan, F.; Bahadur, I.; Salman, M.; Quraishi, M.A.; Verma, C.; Ebenso, E.E. Inhibition performance of Glycine max, Cuscuta reflexa and Spirogyra extracts for mild steel dissolution in acidic medium: Density functional theory and experimental studies. Results Phys. 2018, 10, 665-674. [CrossRef]

26. Shabani-Nooshabadi, M.; Kazemi-Darafshani, M. Root and shoot extracts of Ajuga chamaecistus subsp. scoparia as natural inhibitors for 304 stainless steel corrosion in strong acidic medium. Surf. Eng. Appl. Electrochem. 2017, 53, 560-569. [CrossRef]

27. Zheng, T.; Wang, L.; Liu, J. Corrosion inhibition of levofloxacin and Ce( $\left(\mathrm{NO}_{3}\right)_{3}$ for AA2024-T4 in 3.5\% NaCl. Corros. Eng. Sci. Technol. 2020, 55, 75-82. [CrossRef]

28. Meland, A.K.; Bedeaux, D.; Kjelstrup, S. A Gerischer phase element in the impedance diagram of the polymer electrolyte membrane fuel cell anode. J. Phys. Chem. B 2005, 109, 21380-21388. [CrossRef]

29. Kashkovskiy, R.; Strelnikova, K.; Fedotova, A. Application of electrochemical impedance spectroscopy to study hydrogen sulphide corrosion of steel and its inhibition: A review. Corros. Eng. Sci. Technol. 2019, 54, 493-515. [CrossRef]

30. Hou, B.S.; Zhang, Q.H.; Li, Y.Y.; Zhu, G.Y.; Liu, H.F.; Zhang, G.A. A pyrimidine derivative as a high efficiency inhibitor for the corrosion of carbon steel in oilfield produced water under supercritical $\mathrm{CO}_{2}$ conditions. Corros. Sci. 2020, 164, 108334. [CrossRef]

31. Parthipan, P.; Narenkumar, J.; Elumalai, P.; Preethi, P.S.; Nanthini, A.U.R.; Agrawal, A.; Rajasekar, A. Neem extract as a green inhibitor for microbiologically influenced corrosion of carbon steel API 5LX in a hypersaline environments. J. Mol. Liq. 2017, 240, 121-127. [CrossRef]

32. Tezeghdenti, M.; Etteyeb, N.; Dhouibi, L.; Kanoun, O.; Al-Hamri, A. Natural products as a source of environmentally friendly corrosion inhibitors of mild steel in dilute sulphuric acid: Experimental and computational studies. Prot. Met. Phys. Chem. Surfaces 2017, 53, 753-764. [CrossRef]

33. Sivakumar, P.R.; Srikanth, A.P. Green corrosion inhibitor: A comparative study. Sādhanā 2020, 45, 56. [CrossRef]

34. Isaac, C.; Jiménez, E.; Yane, E.; Martínez, C.; Fonseca, J.G. Flavonoides y sus acciones antioxidantes. Rev. la Fac. Med. 2009, $52,73-75$. 